\title{
The Hot Topic: What we can do about Global Warming, Gabrielle Walker and Sir David King. Douglas and McIntyre (Greystone Books), Vancouver/Toronto, 2008. CA\$15.95.
}

\author{
Geraldine D. Ryan · Jonathan A. Newman
}

Published online: 11 October 2008

(C) Springer Science+Business Media, LLC 2008

In the opening lines of the The Hot Topic: What we can do about Global Warming, authors Gabrielle Walker and Sir David King promise to answer "everything you wanted to know about global warming but were too depressed to ask". And if indeed your knowledge of climate change is limited to popular media sound bites then this book can guide you through the "blizzard of information and misinformation" about global warming with remarkable concision. The book has been hailed as a "beacon of clarity" by Al Gore, while James Lovelock calls for it to become "the authoritative statement on climate change and what to do about it for years to come". This endorsement is perhaps overstated as most scientists and others close to the debate will be familiar with much of its content. This might not be the go-to book for informing academics and policy makers; the science is not as comprehensive as Houghton's, Global Warming: the Complete Briefing, but is, refreshingly, a far cry from the dry and often labyrinthine language of IPCC reports.

The author's credentials speak to its credibility. Gabrielle Walker has a $\mathrm{PhD}$ in Chemistry from Cambridge University, has been climate change editor for Nature and is a contributing editor of New Scientist. Sir David King was the chief scientific adviser to the UK government between 2000 and 2007 and is the Director of the Smith School of Enterprise and the Environment at Oxford University. The Hot Topic is chock-full of information on climate change science, technology, economics and policy and as such is necessarily over-simplified in places, but Walker's journalistic flare and King's first hand experience

G. D. Ryan · J. A. Newman $(\bowtie)$

Department of Environmental Biology, University of Guelph, Guelph, ON, Canada N1G 2W1

e-mail: jnewma01@uoguelph.ca in the policy trenches ensure that the book is factual and grounded in reason, while its simplicity and precision makes it universally accessible.

The book is divided into three parts. Part 1, the Problem, broadly examines the science of climate change, outlining the evidence that climate change is occurring and that humans are responsible. The book admits no uncertainty when addressing this question of responsibility; "wedunnit"; "anybody tells you differently either has a vested interest in ignoring the scientific arguments or is a fool".

All the same, we are urged not to panic. Potential threats to humans and ecosystems are addressed with a focus on those effects which are irreversible versus those that may still be prevented. The subsection Climate Wild Cards considers the likelihood that some of the larger-than-life climate demons will emerge starting with the least likely scenarios, such as the shutdown of the ocean's circulation, and working upwards to the more plausible phenomenon of melting permafrost. In this vein, the authors seem committed to debunking myths on both sides of the argument, stating clearly where scientific arguments may be contentious or equivocal. This is further emphasized in the Appendix under the heading of "Climate Porn" or Disasters that aren't necessarily waiting to happen.

The scientific background is explained in simplistic terms and does not overburden the reader with complicated mechanisms, while still managing to convey the basic message. However, absent from this section was a preliminary explanation of the global carbon budget, which would have put the discussion of carbon sources and sinks into terms and units readily comprehendible by a universal readership.

Part 2 focuses on Technological Solutions to the problems outlined in Part 1 and covers new technologies which may be applied to some of the biggest emitters; industry, 
agriculture, buildings and deforestation, and includes an entire chapter on planes, trains and automobiles for the carbon conscious traveller. The book provides clarification of oft-used but frequently misunderstood technological buzzwords. Bioenergy, carbon capture and storage, geothermal energy, nuclear fusion and wind and solar energy are all discussed in terms of their potential advantages and disadvantages. The word on the controversial issue of biofuels is the same consensus reached by many; not all biofuels are the same. The production of sugar-cane biofuels in Brazil may be hailed as a success but the authors offer a cautionary note on those produced by food crops and those for which the cradle-to-grave emissions are unknown or underreported.

Consistent with the open-mindedness with which the authors approach many of the climate sticking points is a firm advocacy of nuclear energy. Of the many cleaner alternatives to fossil fuels, the technology needed to switch to nuclear is already in place. The authors urge us to critically question the historical hostility towards this "environmental bête noire" which they attribute to early plant designs which were less safe and produced more waste than modern models. Newer plants produce much less waste, with the efficiency of output from US nuclear plants increasing from $60 \%$ to $90 \%$ between 1980 and 2005. New safety features encompass the principle of "walk-away safety" where equipment is designed to automatically shut down should a malfunction occur. With all its perceived flaws, the potential benefits of nuclear power in terms of greenhouse gas emissions would be expeditious and substantial. Indeed, in a later chapter which gives the breakdown of emissions from the world's richest and fastest developing countries, we see that a few of the most developed countries have unexpectedly low per capita emission rates (most notably France and Japan) at least partially due to the dominance of nuclear power in those countries.

Part 3 discusses the political solutions to climate change; an area in which David King is highly experienced. Political and economic strategies such as cap-and-trade emissions and the concept of a global carbon market are treated with personal insight. The economic debate addresses such questions as, how much will it cost to lower global emissions?, how do we pay?, who will pay? and should we pay now or later? This last question was famously and controversially addressed in the Stern Review on the Economics of Climate Change which claimed that tackling the climate change problem now would cost about $1 \%$ of global per-capita annual consumption, but will cost $20 \%$ if we wait. However, Stern received much opposition to this report as the sensitivity of the model was not rigorously tested. The degree of uncertainty in economic models makes it difficult to even begin to predict the future economic impacts of climate change; "the bottom line is that the hard numbers of the future economic costs of climate change depend very sensitively on what are essentially touchy-feely choices. Put that way, any attempt to put a firm price on future damage seems hopeless".

The main criticism of the Hot Topic is perhaps not what was in the book but rather what was omitted. A discussion of population growth was completely absent despite the fact that the world's population has a doubling time of approximately 60 years and is set to reach 9 million by 2042. This fact further emphasizes the shortcomings of economic approaches to emissions such as energy intensity which does not account for total greenhouse gas emissions but instead places emission caps per unit of economic growth. This form of emissions control is most favoured by the Bush administration and is appropriately criticised by King and Walker. The question of ethics was similarly underrepresented and was treated only superficially with assumed answers to complex ethical questions and issues of environmental justice.

Overall the book takes a refreshing middle ground on what David King has controversially stated is the "most severe problem we are facing today, more serious even than the threat of terrorism". Ironic then that such clearheaded insight might place King in the ranks of environmentalist scaremongers according to Myron Ebell, George Bush's climate change adviser, who denounced King as "an alarmist with ridiculous views who knows nothing about climate change". In fact it is worth noting that the book may even have been uncomfortably grounded in optimism for some; the original title The Hot Topic: How to Tackle Global warming and Still Keep the Lights On published in January 2008 was later changed to The Hot Topic: What we can do about Global Warming when a second edition was released 3 months later. 